\title{
Professional perspectives on systemic barriers to admission avoidance: learning from a system dynamics study of older people's admission pathways
}

Bronagh Walsh BSc, PhD, RN

Senior Lecturer, Centre for Innovation \& Leadership in Health Sciences, Faculty of Health Sciences, University of Southampton, Southampton, UK

Valerie Lattimer PhD, MEd, RN

Professor of Health Services Research, School of Nursing Sciences, University of East Anglia, Norwich, UK

Julie Wintrup DipCOT, MBA, EdD

Principal Teaching Fellow, Centre for Innovation \& Leadership in Health Sciences, Faculty of Health Sciences, University of Southampton, Southampton, UK

Sally Brailsford BSc, MSc, PhD

Professor of Management Science, School of Management Sciences, University of Southampton, Southampton, UK

Submitted for publication: 9 January 2014

Accepted for publication: 31 March 2014

Correspondence:

Bronagh Walsh

Faculty of Health Sciences

University of Southampton

SO17 1BJ Southampton

UK

Telephone: 02380597991

E-mail: B.M.Walsh@soton.ac.uk
WALSH B., LATTIMER V., WINTRUP J. \& BRAILSFORD S. (2014) Professional perspectives on systemic barriers to admission avoidance: learning from a system dynamics study of older people's admission pathways. International Journal of Older People Nursing doi:10.1111/opn.12056

Background. There is debate worldwide about the best way to manage increased healthcare demand within ageing populations, particularly rising rates of unplanned and avoidable hospital admissions.

Objectives. To understand health and social care professionals' perspectives on barriers to admission avoidance throughout the admissions journey, in particular: the causes of avoidable admissions in older people; drivers of admission and barriers to use of admission avoidance strategies; and improvements to reduce unnecessary admissions.

Design. A qualitative framework analysis of interview data from a System dynamics (SD) modelling study.

Methods. Semi-structured interviews were conducted with twenty health and social care professionals with experience of older people's admissions. The interviews were used to build understanding of factors facilitating or hindering admission avoidance across the admissions system. Data were analysed using framework analysis.

Results. Three overarching themes emerged: understanding the needs of the patient group; understanding the whole system; and systemwide access to expertise in care of older people. There were diverse views on the underlying reasons for avoidable admissions and recognition of the need for whole-system approaches to service redesign.

Conclusions. Participants recommended system redesign that recognises the specific needs of older people, but there was no consensus on underlying patient needs or 
specific service developments. Access to expertise in management of older and frailer patients was seen as a barrier to admission avoidance throughout the system.

Implications for practice. Providing access to expertise and leadership in care of frail older people across the admissions system presents a challenge for service managers and nurse educators but is seen as a prerequisite for effective admission avoidance. System redesign to meet the needs of frail older people requires agreement on causes of avoidable admission and underlying patient needs.

Key words: admission avoidance, frailty, framework analysis, hospital admissions, older people, system dynamics modelling

\section{What does this research add to existing knowledge in gerontology?}

- Professionals' assumptions about patient needs and service development were not shared across professional groups and services.

- Although professionals acknowledged the need for whole-system service redesign, this study revealed that professionals had only a partial understanding of the whole admissions system.

- Lack of expertise in care of older people was seen as a systemwide limitation on development and delivery of admission avoidance services.

\section{What are the implications of this new knowledge for nursing care with older people?}

- The nursing profession must consider how expertise and leadership in care of older people can be developed across the healthcare system.

- Nurses with expertise in care of older people to disseminate and develop effective interventions which acknowledge the specific needs of frail older people.

\section{How could the findings be used to influence policy or practice or research or education?}

- Whole-system approaches, which use knowledge and expertise from across services and professions to build system-level understanding, are necessary for service planning.

- Service managers should consider how available expertise should be best deployed at key points in the patient journey.

- Inter-disciplinary work is needed to build a consensus on the causes of and most effective responses to avoidable admission.

\section{Introduction}

Ageing populations increase demand for health care, largely as a consequence of increased prevalence of chronic disease. Managing this demand, particularly unplanned hospital admissions, has become a priority for health services worldwide (Singh, 2008; World Health Organisation, 2008; Gillam, 2010; Robinson, 2010; White, 2010; Comptroller \& Auditor General, 2013). Nurses and nursing services are often at the centre of admission avoidance strategies. In recent years, a range of services, many led or delivered by nurses, have been introduced to reduce unplanned hospital admission in older people. Although approximately 20-35\% of emergency admissions are thought to be avoidable if appropriate alternative services are available (McDonagh et al., 2000; Purdy et al., 2009), admission avoidance interventions have failed to reduce unplanned hospital admissions in older people (Health Services Management Centre, 2006; Wanless et al., 2007; Kmietowicz, 2010; Comptroller \& Auditor General, 2013). The provision of effective alternatives to acute admission remains a key challenge for the nursing profession. Given financial pressures on public services and recent calls to prioritise research on the optimal organisation of prehospital care (Carpenter et al., 2011), it is timely to consider how services might be best organised to optimise admission avoidance for older people and particularly the role of nursing in achieving this goal.

Ill-defined conditions provide a useful model for understanding avoidable admissions (Wanless et al., 2007; Walsh et al., 2008; Jones, 2009). These admissions ${ }^{1}$ are rising rapidly in older people, account for a substantial proportion of unplanned medical admissions internationally (Walsh et al., 2007, 2011; Condelius et al., 2008) and are associated with adverse outcomes (Hastings et al., 2009), ambulatory care sensitive conditions (Purdy et al., 2009), admission to

\footnotetext{
${ }^{1}$ Those coded with an R prefix within Chapter XVIII 'Symptoms, signs and abnormal laboratory findings' of the ICD-10 (WHO, 1994).
} 
nursing homes (van Rensbergen \& Nawrot, 2010) and high service use (Condelius et al., 2008). It has also been argued that they represent a failure of community management and their prevalence necessitates examination of the services provided for older people at every stage of the admission process (Thomas, 2008). This analysis utilised data from a system dynamics (SD) modelling study which explored admission pathways for older people with ill-defined conditions to explore professionals' perspectives on admission avoidance for older people. Given that these functional and symptom-based diagnoses may lend themselves to nursing intervention, this analysis has particular relevance for the nursing profession.

\section{Aims and objectives}

This secondary qualitative analysis aimed to explore professionals' views on: the drivers of avoidable admission in older people; the barriers to and facilitators of admission avoidance operating within different parts of the system; and system improvements to improve admission avoidance strategies.

\section{Methods}

This paper presents a qualitative analysis carried out within a larger programme of work using Operations Research (OR) methods, specifically system dynamics (SD) modelling (Dangerfield, 1999; Rosenhead \& Mingers, 2001), to explore the organisation of services for admission and admission avoidance. SD modelling is a well-established approach to describing complex systems and may, in its quantitative phase, be used for predictive simulation modelling of different service organisation scenarios. SD modelling has been used to explore the complexities of healthcare demand
(Lattimer et al., 2004; Taylor et al., 2005) and is consistent with the whole-systems approaches recommended as a research priority in emergency care (University of Sheffield Medical Care Research Unit, 2010). The quantitative simulation phase is informed by a qualitative phase, which combines structural analysis of organisational processes with personal accounts of system functioning to deepen understanding of problems and generate potential solutions. In the qualitative phase, the intention is for both researchers and participants to develop their understanding of the system and therefore useful insights may emerge from this phase (Taylor et al., 2005).

The SD programme of work utilised a qualitative phase designed to build a detailed map of older people's actual and potential pathways through the urgent care system (Fig. 1) for a quantitative modelling exercise. Beyond this original purpose, the interviews represented a rich data source, as described by Taylor et al. (2005), relating to decision-making and understanding around avoidable admission, which forms the basis of this secondary analysis.

The qualitative data used for this analysis resulted from semi-structured interviews covering the following topics: system components, routes through the system for older people, relationships between components, bottlenecks, factors shaping the current system, decision-making about transitions, how services could/should be structured to best meet patient needs, the nature of patient needs, barriers to change, capacity of the system and the role of the professional. These topics were developed with the SD programme advisory group. These domains also provided an organising structure for the framework analysis of the data. Interviews centred on a draft system map printed on A3 paper and used, in conjunction with the interview topic guide, as a focus for discussion. The starting point for the interviews was to

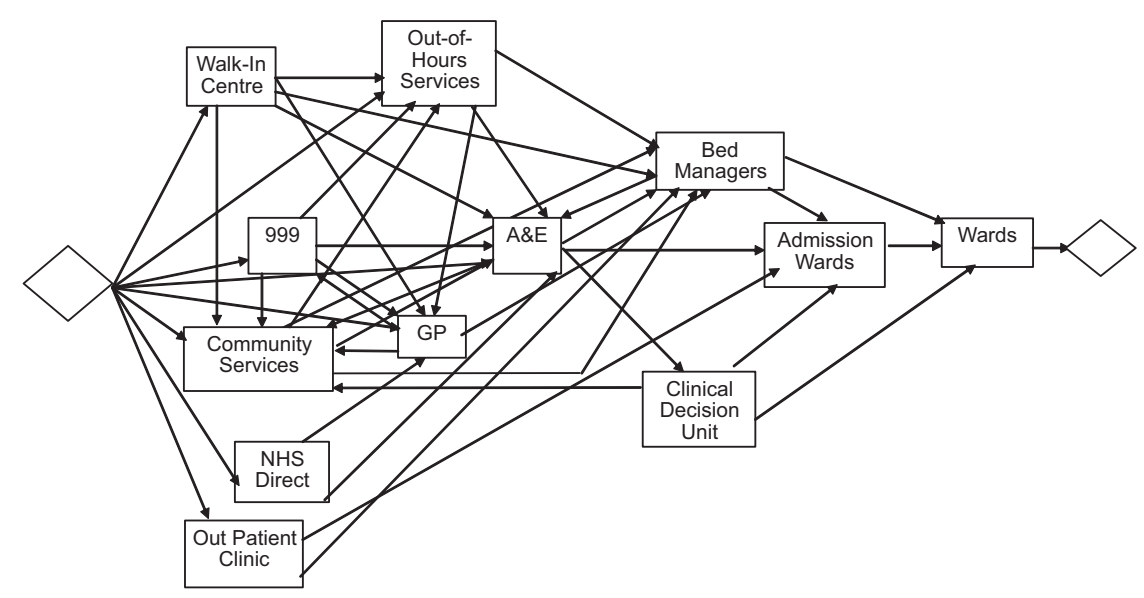

Figure 1 Map of patient pathways through the unscheduled care system. 
identify the routes through which patients could be directed. The participants were encouraged to add to/modify the map by drawing new components, links or influences and annotating the map. The interviews continued, using progressively detailed conceptual maps, until no new information was being added to the map. This final map formed the basis of a computer model (in preparation). Through discussion of these issues in relation to the map, factors influencing admission decisions were elucidated.

Interviews were carried out within one regional health economy in England, comprising acute hospitals, integrated health and social care services, ambulance and out-of-hours services and the voluntary sector. Professional stakeholders, chosen because of their involvement in older people's admissions, were recruited by telephone and e-mail from key organisations within this geographical area, including NHS acute hospital and primary care providers, ambulance service, out-of-hours $(\mathrm{OOH})$ services, general practitioner (GP) services, social and voluntary care agencies. Recruitment was initially by purposive sampling and then by further snowball sampling ensuring that, as participants identified additional components of the urgent care system, professionals with experience in these areas could be recruited and that sampling was not limited by preconceptions about the relevant components of the system. An important aspect of older people's unplanned admissions is that they will encounter a range of specialist and generic services and professionals, and the sample reflects this range. The participants were therefore able to provide insight into barriers to admission avoidance across the community, unscheduled care, emergency, intermediate and acute care and specialist older people's services. Older people were defined as aged 65 and over, but discussion was not restricted to a particular type of patient or clinical setting, allowing different perspectives and experiences to be explored.

Interviews were carried out by a researcher with clinical and research experience of care of older people (BW). They lasted approximately one hour, were recorded, and each system map was extensively annotated during each interview. Both the recordings and their accompanying annotated system maps were used for this secondary framework analysis, which was carried out manually due to the need to relate comments to the annotated system map. Intertwined with the rational, purposeful collection of data on the patient pathways, interviews generated rich descriptions of the system as experienced by health professionals (Rapley, 2004). In seeking to explore how organisational and patient factors impact upon admission decisions, the researcher created space for views and beliefs to be shared, particularly about needs and concerns underlying such admissions. This active approach to data collection allowed the range and complexity of meanings to be revealed and minimised the influence of predetermined agendas (Holstein \& Gubrium, 1995). This was important given the need to develop an understanding of the system and its influences as they operate in practice rather than as they are conceptualised by policymakers.

A framework analysis was adopted (Green \& Thorogood, 2004; Ritchie \& Lewis, 2006) because it facilitates exploration of issues of interest for policy-makers and service managers, whilst allowing new themes to emerge and is suited to research with specific research questions about $a$ priori issues, as in this case. Using the sequence of analysis described by Pope et al. (2006), content was first indexed and then allocated to topic groups identified within the interview framework and overarching themes were identified. The data were analysed independently by two members of the research team (BW and JW), and agreement was reached on index themes. Prespecified domains were used as an organising framework for the analysis, with thematic analysis exploring issues emerging across these domains (Table 1). The framework analysis approach ensures that data pertaining to all the issues of interest are captured, but that a comprehensive analysis is performed (Ritchie \& Lewis, 2006). In this paper, we present the findings in relation to professionals' views on factors underlying unplanned and avoidable admission and the systemic barriers to admission avoidance.

\section{Ethical issues}

Interviewees volunteered to participate and all gave informed consent. Due to the unique nature of some roles, in the following text, participants are identified only by professional group to maintain confidentiality.

\section{Findings}

Twenty-five people were approached to participate, of whom three (all nurses) refused and two consented but could not participate due to work commitments. Twenty people were interviewed, including nurses (5), doctors (3), specialist nurses (4), paramedics and emergency care practitioners (3) and health and social care service managers (5). Their workplaces included acute admissions, including ED, internal and geriatric medicine acute wards (7), community health services (7), social care and voluntary sector (2), out-of-hours and ambulance services (4), although eight had experience in more than one service or sector. Due to the diversity of services involved in admission of older people to hospital, few of the participants worked exclusively with the older age group, but all had 
Table 1 Themes emerging within the analysis framework

\begin{tabular}{|c|c|c|c|}
\hline \multirow[b]{2}{*}{ Framework domains } & \multicolumn{3}{|l|}{ Index themes } \\
\hline & $\begin{array}{l}\text { Understanding the needs of the } \\
\text { patient group }\end{array}$ & $\begin{array}{l}\text { Understanding the whole } \\
\text { system }\end{array}$ & $\begin{array}{l}\text { Systemwide access to expertise in care of older } \\
\text { people }\end{array}$ \\
\hline $\begin{array}{l}\text { Reasons for avoidable } \\
\text { admission }\end{array}$ & $\begin{array}{l}\text { Ageing population Atypical and } \\
\text { complex needs }\end{array}$ & $\begin{array}{l}\text { Lack of proactive care } \\
\text { Lack of continuity }\end{array}$ & $\begin{array}{l}\text { Lack of knowledge about frail older people and their } \\
\text { needs }\end{array}$ \\
\hline Drivers of admission & Risk avoidance & $\begin{array}{l}\text { Complexity and } \\
\text { fragmentation of services } \\
\text { Lack of alternatives to } \\
\text { admission }\end{array}$ & $\begin{array}{l}\text { Lack of skills and knowledge to manage the patient } \\
\text { group in the community }\end{array}$ \\
\hline $\begin{array}{l}\text { Barriers to admission } \\
\text { avoidance }\end{array}$ & $\begin{array}{l}\text { Failure to recognise patient } \\
\text { demographic }\end{array}$ & Lack of appropriate services & $\begin{array}{l}\text { Lack of elderly care expertise in service planning and } \\
\text { delivery }\end{array}$ \\
\hline System improvements & Services for the frail elderly & $\begin{array}{l}\text { Increased non-acute } \\
\text { capacity } \\
\text { Improved continuity } \\
\text { Whole-system reform }\end{array}$ & $\begin{array}{l}\text { Need for elderly care expertise and leadership in } \\
\text { service planning }\end{array}$ \\
\hline
\end{tabular}

regular contact with older people experiencing emergency medical admissions, the patient group of interest.

The following themes relating to systemic issues emerged from the framework domains (Table 1) through analysis of both interviews and the annotated draft conceptual maps developed in each interview: understanding the needs of the patient group; understanding the whole system; and systemwide access to expertise in care of older people. It can be seen that themes cut across the domains and have broad relevance to the issue of admission avoidance for older people.

\section{Understanding the needs of the patient group}

Participants agreed that an ageing population, and its associated increase in prevalence of chronic disease, disability and frailty, is a driver of unplanned admissions. This view is broadly in line with UK Department of Health policy, which promotes chronic disease management as a means to reduce avoidable hospital admissions. However, this analysis revealed complex interpretations of the nature and impact of ensuing health problems. Perceptions of the relationship between ageing, chronic disease and hospital admissions differed according to the setting and amount of experience in caring for older people. Some participants, largely from acute and social care sectors, reported that the ageing population experiences high levels of social problems, loneliness and carer burnout. Participants therefore assumed that admission, particularly for ill-defined conditions, results from these problems:

the classic 'gone off feet' diagnoses, which often turns out to be what I would call a social admission (P10, nurse)

However, for other participants, notably those with experience in care of older people, there are physical issues specific to older patients, characterised by multiple chronic illnesses, non-specific disease presentation and complexity of symptoms. For this group of professionals, both patients and non-specialist healthcare professionals lack understanding about what to expect in terms of normal fluctuations in condition, the nature of chronic diseases, their signs and symptoms, and needs emerging from multiple morbidity and frailty in older people. In addition, some participants distinguished between acute illness, requiring admission to acute hospital, and exacerbation or deterioration of the chronic condition. The concept of unstable chronic conditions appeared to be important in this view, and the term 'frailty' was widely used by these participants. For many participants, limited proactive chronic disease management was therefore explicitly identified as a factor predisposing to admission:

A lot of these patients will have chronic, long-term conditions that are not stable (P11, Manager)

An ageing population was therefore viewed as resulting in changing healthcare needs that are, crucially, not recognised within systems historically set up for a different, more acute, patient population:

you get a higher percentage of older people in a medical ward now ... but it [the system] doesn't cater for them now (P05, Nurse)

For a small number of the participants with specific expertise in care of older people, the policy assumption that such admissions are avoidable was questionable. They argued that multiple pathology, non-specific deterioration and complex symptoms might necessitate hospitalisation to allow proper investigation. Their view was that such admissions are only seen as problematic when viewed outside this paradigm, 
for example, in general or emergency medicine settings. They argued that admission avoidance might be more rather than less difficult in these patients due to their complexity, a direct contrast to the current policy perspective.

Importantly for planning admission avoidance services, this theme generated the greatest diversity of views, and there was no consensus on the underlying reasons for avoidable admission. Participants' conceptualisations of these admissions covered social, psychological and physiological aspects of ageing. Professionals with specific expertise in care of older people had a greater focus on the physiological impact of multi-morbidity and the consequences for symptom experience. This appeared to drive their more complex, multi-faceted explanations for this type of admission, which they felt were not reflected in current approaches within the admissions system and were not understood by other health professionals.

\section{Understanding the whole system}

An important finding was that few participants advocated development of new services. Participants felt that capacity of, and access to, existing services and the ability of services to meet the specific needs of older people was more important. Interviewees felt that a lack of supportive services for patients, poor continuity of care and lack of information available to urgent care services reinforced risk-averse behaviours, with consequences for admission rates. Many participants felt that this had become a driver of admissions for frail older people and that services needed to be redesigned for this group to ensure that continuity of care was possible. The majority of participants from all professional groups emphasised that lack of capacity in community-based nursing services was a major limiting factor in admission avoidance. Related to this was the observation that services fail to meet the needs of older people due to the inability to access care as opposed to medical assessment or treatment. Improved access to and capacity of intermediate care would, it was argued, remove a major barrier to admission avoidance:

sometimes they just need taking care of, they need someone to take care of them (P04, Manager)

Even where admission avoidance services were in place, participants highlighted the increasing complexity and fragmentation of unscheduled and community care services. Service complexity was characterised by the proliferation of services, different access and referral procedures over time and geographically, varied criteria for admission to services and boundary issues between health and social care. For example, provision outside normal GP hours appeared to be a particular barrier to admission avoidance, and the loss of the
GP gatekeeper function during these periods was thought to drive admissions, but no other professional group or service had successfully adopted this function:

ideally they [ill-defined patients] wouldn't go through out-of-hours ... I mean ideally they'd be seen by a GP who knows them (P01, Doctor)

The degree of complexity is reflected in the conceptual map that emerged from the system dynamics modelling study (Fig. 1). It should also be noted that elements of this final map are representative of underlying sub-systems which are themselves very complex, for example 'out of hours care'. Complexity and fragmentation of services resulted in professionals feeling that specialised, local knowledge was required to navigate the system:

there are some really marked discrepancies between PCTs (primary care trusts)... and it's really difficult as a clinician to navigate - to have information and to know what's accessible, who's eligible (P03, Nurse)

Many participants felt that, in some situations, inappropriate admission was therefore inevitable.

Local and partial development of services was thought to add to complexity and fragmentation. Whilst patient pathways tend to be conceptualised as a linear sequence of clearly defined steps at an organisational level, the professionals described their experience of navigating a loose network of poorly defined components. There was a sense that, rather than introducing new interventions and services, more ambitious system reform was required. Some participants indicated that one of the problems with the emergency care system is the piecemeal approach to improvement which 'bolts on' new procedures and services to existing systems and where redesign of the whole system is not possible. Sector boundaries and the imposition of competition and markets were seen as compounding this situation, reducing continuity of care and preventing patient-centred care from developing: in terms of service redesign nobody ever thinks big enough ... and it's all too piecemeal (P03, Nurse)

However, few nurses described a sense of agency or a belief in their own ability to influence change, and none of the interviewees thought that there was sufficient political will or leadership required to facilitate this change.

\section{Systemwide access to expertise in care of older people}

Participants identified lack of expertise (or access to expertise) in care of older people as a limiting factor operating across the system. This was felt to be a key driver 
of the admissions journey. Practitioners felt that more appropriate assessment and management could only be provided in an area where such expertise was guaranteed, in most cases the acute hospital. This was perceived to be a problem at a number of levels. For generalists, such as ambulance service staff or GPs, and for more inexperienced professionals, the problem was felt most acutely in relation to accessing expert opinion at the point of decision-making about admission:

you also need someone with the expertise to make that decision [not to admit] of course, which is usually a geriatrician, a consultant geriatrician (P01, Doctor)

The second problem was a systemwide lack of capacity to take on the challenge of proactive chronic disease management for older people in the community, for rapid assessment and management decisions and to develop services for admission avoidance:

the nurses are not clinically advanced enough in some aspects of the care to manage the complex conditions that they need to (P08, Nurse)

This view was borne out by comments from less experienced or more generalist clinicians:

There's nothing to focus on, there's nothing to build around ... and ... you're having to focus on symptoms really, which is harder to deal with (P19, Nurse)

Lack of expertise about older people was also seen as a major barrier to effective service redesign. There was frustration with a perceived lack of leadership from within the health service and that older people's services lacked the capacity to provide this leadership, which became a vicious circle in attracting high-calibre people to the field:

a lot of staff ... they don't see it as a dynamic area to work in ... unless we can really raise the profile and say we're being dynamic ... I don't think there's a drive to do it, you've got to have the leadership and I think there's a lack of leadership (P10, Nurse)

Participants advocated improved training opportunities in care of older people, access to telephone support, more availability of elderly care expertise in the community, or even specialist ED units. However, the poor profile of care of older people and a lack of critical mass in terms of expertise in this area were thought to be limiting factors in developing or reforming services.

\section{Discussion}

This analysis of the views of health and social care professionals on avoidable admission of older people is unusual in taking a whole-system perspective. The most important finding is that underlying assumptions about patient needs and problems were not shared across the service or within or between professional groups. Underlying widespread agreement that it is necessary to reduce admissions because of adverse consequences for both patients and the health service, there are quite different conceptions of health, illness, ageing, the role of service providers and the underlying physical and social problems underpinning avoidable admissions in older people. Such beliefs will undoubtedly influence perceptions of appropriate service organisation, an issue reflected in the lack of consensus on how to improve the system. In this context, it is worth noting that the assumptions about avoidable admissions underlying current policy and practice, whilst largely accepted as plausible by professionals, were more likely to be questioned by those with expertise in care of older people (Walsh et al., 2008; Jones, 2009).

The majority of participants, and especially those with experience of older people's or community settings, recognised that frail older people have specific and atypical needs that are not easily met within a system focused on clearly defined acute problems, a view supported by other work on older people in unscheduled care settings (Voyer \& SychNorrera, 2003; Kelley et al., 2010; The King's Fund's, 2012). Whilst the 'atypical' needs of frail older people were sometimes viewed as the manifestation of psychological or social needs, specialists in care of older people felt that the underlying pathological processes of ageing and chronic disease were responsible for complex symptom presentations. This distinction, between viewing 'atypical' presentation as a problem relating to inappropriate admission, as against seeing it as 'typical' for older people who are ill, has been highlighted elsewhere (Oliver, 2008). The latter view is accepted in medicine for older people and is also compatible with what is known about the frailty disease trajectory (Covinsky et al., 2003; Lunney et al., 2003; Dy \& Lynn, 2007). The concept of frailty may therefore be a useful model to consider in both staff and service development beyond care of older people settings. This approach could help resolve the issues around managing symptoms and complex problems that were raised by interviewees, but does not currently guide service organisation and workforce training other than in medicine for older people (Rockwood, 2006; Dorrell et al., 2011; Oliver, 2012). The comprehensive geriatric assessment (CGA) model, with its emphasis on symptom management, function and management of polypharmacy, could resolve this conflict. CGA has proven benefit for older people, but is not embedded across the healthcare system (Oliver, 2012), and it is unclear to what extent other professionals, including 
nurses, can contribute to delivering this model. This analysis highlighted the need for systems to be designed for their actual users and for providers of care to understand those needs (Rockwood, 2006; Dorrell et al., 2011; Oliver, 2012). Further work is needed to explore the workforce training needs and the relative contribution of different professional groups.

In addition to the lack of clarity about older people's needs, interviewees described complex and fragmented systems of care that were detrimental to older people. The complexity of the system, and the potential difficulty of navigating through the system, was reflected in the conceptual map that emerged from the interviews (Fig. 1). Complexity and lack of continuity are well-known barriers to provision of high quality care and have been associated with a variety of adverse outcomes including hospital admission (Saultz \& Lochner, 2005). However, an important finding of this study, which may be important for exploring the problem of continuity of care with this patient group, was that professionals themselves had only a partial understanding of the entire system and that they were surprised by the complexity of the system map. It is unlikely that this particular issue would have emerged other than through the SD approach; in developing the conceptual map and through the framework analysis, these interviews allowed a diversity of views to emerge and exposed the partial understanding of the system that might not have been identified by other qualitative approaches. There are potential risks attached to service development based on a limited understanding of systemic problems. Learning from the SD approach was instructive, in that the process revealed to participants that whole-systems solutions were necessary to address rising admission in an ageing population. However, participants based recommendations for service development on this necessarily limited view whilst at the same time acknowledging the need for systemwide approaches to service redesign. This is consistent with findings from other SD modelling exercises, which often reveal accurate knowledge about parts of the system but poor understanding of the overall system behaviour that will result from a sequence of local actions (Forrester, 1991). This aspect of the study provides an unusual perspective within health services research and has important implications for policy-makers in this field within and beyond the United Kingdom. The findings of this study support the claims made elsewhere (Health Services Management Centre, 2006; Dorrell et al., 2011; Comptroller \& Auditor General, 2013) that whole-systems approaches are required to deal with systemic problems in unscheduled care and that fundamental reform is needed to meet the needs of older people with complex health problems. However, if system redesign is to be successful, a degree of system-level understanding will be necessary in both planning and implementing new service configurations. The conceptual map arrived at through these interviews could be a useful learning tool to aid understanding of the whole system and unintended downstream consequences of change.

A fundamental issue emerging from the interviews was that a lack of expertise in care of older people was a systemwide limiting factor, both for current services and for service design and development. The need for staff education to achieve service development has been noted elsewhere (Wanless et al., 2007; Oliver, 2008; Kelley et al., 2010; Carpenter et al., 2011) and must be seen as a prerequisite for effective service planning and delivery, but there is a danger that system reform focuses on organisation of services and interventions whilst failing to consider the workforce implications of widespread change (The King's Fund's, 2012). Without sufficient training, education and attention to implementation, it is likely that professionals will continue to act in entrenched ways despite organisational restructuring. Further, Heyman et al. (2004) have described the phenomenon of secondary complexity arising from organisational simplification in relation to health services for adults with learning disabilities. This study suggests that a similar process may be in operation in relation to health care for older people, where simplified and standardised care, often provided by less expert individuals, cannot meet the complex needs of many service users (e.g. frail older people), necessitating additional services and processes to meet complex needs. The increasing reliance on unregulated support staff and the implications for care quality are now becoming more widely acknowledged, but the systemic effects arising from this secondary complexity in relation to care of older people may not be fully recognised.

It is not clear how the nursing profession can nurture the required expertise and leadership in this field. Care of older people continues to be a relatively small specialty, and the negative perceptions of working with older people alluded to by many participants are a difficult barrier to overcome in many professions (Oliver, 2008). A narrative around care of older people that emphasises 'fundamental' or 'basic' care may be detrimental, both in reinforcing views that this specialty is undemanding and in leaving newly qualified staff unprepared for the challenge of managing the complex needs described within this study. Policymakers and education providers are increasingly seeing the importance of care of older people, but the impact of current curriculum developments and the increased research efforts in relation to older people may not be felt for some 
years. Incentives to specialising in care of older people may be needed at the early career stage or for professionals wishing to change discipline. In the meantime, one of the most important lessons emerging from the study is the necessity of organising care to allow access to experts at key points in the admission process, either in person or via telephone.

This study comprised a secondary framework analysis of qualitative data collected for a SD modelling programme, and, as such, it has some limitations, not least its focus on understanding patient pathways and decision-making from the perspective of professionals. The patient perspective was beyond the scope of the SD modelling exercise and should be addressed in future work. Some groups were under-represented in the sample, particularly hospital bed managers and GPs, although the three doctors interviewed had experience of both primary and secondary care and various aspects of the admission system. Finally, the study was carried out in a particular geographical region of the English NHS and findings related to a specific time and place. However, the study setting is considered to be typical of England as a whole, both in terms of organisation of care and demographic profile of the population (Hampshire NHS Primary Care Trust, 2007). Recent policy and research evidence suggests that the problems identified in this study remain current. Relevance across the NHS and elsewhere is therefore through the shared demographic challenge and policy landscape.

\section{Conclusions}

This analysis of interview data from a system dynamics modelling exercise explored health professionals' views of about older people admitted with ill-defined conditions as a way of understanding systemic barriers to admission avoidance. Despite widespread agreement amongst participants about the need for admission avoidance, the participants expressed diverse views about the drivers of avoidable admission and consequently the service developments needed to reduce demand. Participants were, however, in agreement that the fragmented system of care currently in operation was detrimental to meeting the needs of older people with complex health problems. Many participants advocated whole-system redesign that recognises the needs of older people. The interviews revealed concern about the lack of expertise within the healthcare system in relation to care of those with frailty and complex chronic conditions. Building expertise across the system is necessary to the success of initiatives to reduce demand, which will otherwise fail to have a substantial impact on rising rates of unplanned hospital admissions in older people.

\section{Implications for practice}

- Professionals expressed conflicting views about factors leading to admission.

- There was no consensus on what is required of admission avoidance services.

- Lack of expertise in care of older people is a major limiting factor across the admissions system.

- Conceptualisations of frailty and decline which underpin medical education in this area are not widely used in other professions including nursing.

\section{Contributions}

Study design: VL, SB; data collection and analysis: BW, JW and manusript preparation: VL, SB, BW, JW; conceived the project: BW.

\section{References}

Carpenter C.R., Shah M.N., Hustey F.M., Heard K., Gerson L.W. \& Miller D.K. (2011) High yield research opportunities in geriatric emergency medicine: pre-hospital care, delirium, adverse drug events and falls. The Journals of Gerontology. Series A, Biological Sciences and Medical Sciences 66A, 775-783.

Comptroller \& Auditor General (2013) Emergency Admissions to Hospital: Managing the Demand. National Audit Office, London.

Condelius A., Edberg A.K., Jakobsson U. \& Hallberg I.R. (2008) Hospital admissions among people $65+$ related to multimorbidity, municipal and outpatient care. Archives of Gerontology \& Geriatrics 46, 41-55.

Covinsky K.E., Eng C., Lui L.Y., Sands L.P. \& Yafffe K. (2003) The last 2 years of life: functional trajectories of frail older people. Journal of the American Geriatrics Society 51, 492-498.

Dangerfield B.C. (1999) System dynamics applications to European health care issues. Journal of the Operational Research Society 50, 345-353.

Dorrell S., Milburn A., Kerr D. \& Moyer B. (2011) Passing judgement on Lansley's vision. Health Services Journal 121, 14-17.

Dy S. \& Lynn J. (2007) Getting services right for those sick enough to die. British Medical Journal 334, 511-513.

Forrester J.W. (1991) System dynamics and the learning from 35 years. In The Systemic Basis of Policy-Making in the 1990s (DeGreene K.B. ed.). MIT Press, Cambridge, Available at: http:// clexchange.org/ftp/documents/system-dynamics/SD1991-4SDand Lessonsof35Years.pdf (accessed 25 April 2014).

Gillam S. (2010) Rising hospital admissions. Can the tide be stemmed? British Medical Journal 340, c636.

Green J. \& Thorogood N. (2004) Qualitative Methods for Health Research. Sage Publications, London. 
Hampshire NHS Primary Care Trust (2007) Public Health Annual Report 2006-2007. Hampshire NHS Primary Care Trust, Southampton.

Hastings S.N., Whitson H.E., Purser J.L., Sloane R.J. \& Johnson K.S. (2009) Emergency Department discharge diagnosis and adverse health outcomes in older adults. Journal of the American Geriatrics Society 57, 1856-1861.

Health Services Management Centre (2006) Reducing Unplanned Hospital Admissions. Health Services Management Centre, Birmingham.

Heyman B., Swain J. \& Gillman M. (2004) Organisational simplification and secondary complexity in health services for adults with learning disabilities. Social Science \& Medicine 58, 357-367.

Holstein J.A. \& Gubrium J.F. (1995) The Active Interview. Sage, California, CA.

Jones R. (2009) Trends in emergency admissions. British Journal of Healthcare Management 15, 188-196.

Kelley M.L., Parke B., Jokinen N., Stones M. \& Renaud D. (2010) Senior-friendly Emergency Department care: an environmental assessment. Journal of Health Services Research and Policy 16, 612.

Kmietowicz Z. (2010) Hospitals will be fined for emergency readmissions, says Lansley. British Medical Journal 340, c3079.

Lattimer V., Brailsford S., Turnbull J., Tarnaras P., Smith H., George S., Gerard K. \& Maslin-Prothero S. (2004) Reviewing emergency care systems I: insights from system dynamics modelling. Emergency Medical Journal 21, 685-691.

Lunney J.R., Lynn J., Foley D., Lipson S. \& Guralnik J.M. (2003) Patterns of functional decline at the end of life. Journal of the American Medical Association 289, 2387-2392.

McDonagh M.S., Smith D.H. \& Goddard M. (2000) Measuring appropriate use of acute beds - a systematic review of methods and results. Health Policy 53, 157-184.

Oliver D. (2008) 'Acopia' and 'social admission' are not diagnoses: why older people deserve better. Journal of the Royal Society of Medicine 101, 168-174.

Oliver D. (2012) Transforming care for vulnerable older people in hospital: physicians must embrace the challenge. Clinical Medicine 12, 1-5.

Pope C., Ziebland S. \& Mays N. (2006) Analysing Qualitative Data. In Qualitative Research in Healthcare, 3rd edn (Pope C. \& Mays N. eds). BMJ Books, London, pp. 63-81.

Purdy S., Griffin T., Salisbury C. \& Sharp D. (2009) Ambulatory care sensitive conditions: terminology and disease coding need to be more specific to aid policy-makers and clinicians. Public Health 123, 169-173.

Rapley T. (2004) Interviews. In Qualitative Research Practice (Seale C., Gobo G., Gubrium J. \& Silverman D. eds). Sage, London, pp. $15-33$.

van Rensbergen G. \& Nawrot T. (2010) Medical conditions of nursing home admissions. BMC Geriatrics 10, 46.

(Ritchie J. \& Lewis J. eds) (2006) Qualitative Practice: A Guide for Social Science Students and Researchers. Sage Publications, London.

Robinson P. (2010) Are Hospital Admissions Out of Control?. CHKS, Alcester.
Rockwood K. (2006) What would make a definition of frailty successful? Age and Ageing 34, 33-34.

Rosenhead J. \& Mingers J. (2001) Rational Analysis for a Problematic World Revisited. Wiley, Chichester.

Saultz J.W. \& Lochner J. (2005) Interpersonal continuity of care and care outcomes: a critical review. Annals of Family Medicine 3, 159-166.

Singh D. (2008) How can chronic disease management programmes operate across care settings and providers? World Health Organisation Regional Office for Europe and Regional Observatory on Health Systems and Policies. Available at: http://www. euro.who.int/en/health-topics/Health-systems/primary-health-care/ publications/pre-2009/how-can-chronic-disease-managementprogrammes-operate-across-care-settings-and-providers-whoeurope2008 (accessed 25 April 2014).

Taylor K., Dangerfield B. \& LeGrand J. (2005) Simulation analysis of the consequences of shifting the balance of health care: a system dynamics approach. Journal of Health Services Research \& Policy 10, 196-202.

The King's Fund (2012) The Care of Frail Older People With Complex Needs: Time for a Revolution. King's Fund, London.

Thomas M. (2008) Are we counting the right thing? Age and Ageing 37, 360-361.

University of Sheffield Medical Care Research Unit (2010) Building the Evidence-Base in Pre-Hospital Urgent and Emergency Care. A Review of Research Evidence and Priorities for Future Research. Department of Health, London.

Voyer P. \& Sych-Norrera L. (2003) Challenges in emergency room care for the elderly: if health services today do not adequately address our ageing population, tomorrow's reality in emergency rooms will be overwhelming. Canadian Nurse 99, 22-26.

Walsh B., Roberts H. \& Hopkinson J. (2007) Emergency hospital admissions for ill-defined conditions amongst older people: a review of the literature. International Journal of Older People Nursing 2, 270-277.

Walsh B., Roberts H.C., Nicholls P.G. \& Lattimer V.A. (2008) Trends in hospital inpatient episodes for signs, symptoms and ill-defined conditions: observational study of older people's hospital episodes in England, 1995-2003. Age and Ageing 37, 455-458.

Walsh B., Roberts H.C. \& Nicholls P.G. (2011) Emergency hospital admissions of older people due to ill-defined (R-coded) conditions: retrospective analysis of hospital admissions data. BMC Geriatrics 11, 62.

Wanless D., Appleby J., Harrison A. \& Patel D. (2007) Our Future Health Secured? A Review of NHS Funding and Performance. King's Fund, London.

White C. (2010) Hospital admissions rise by $6 \%$ in England. British Medical Journal 340, c456.

WHO (1994) International Classification of Diseases Version and Related Health Problems. 10th Revision. WHO, Geneva.

World Health Organisation (2008) World Health Report: Primary Health Care. Now More Than Ever. WHO, Geneva. Available at: http://www.who.int/whr/2008/en/index.html (accessed 24 April 2014). 